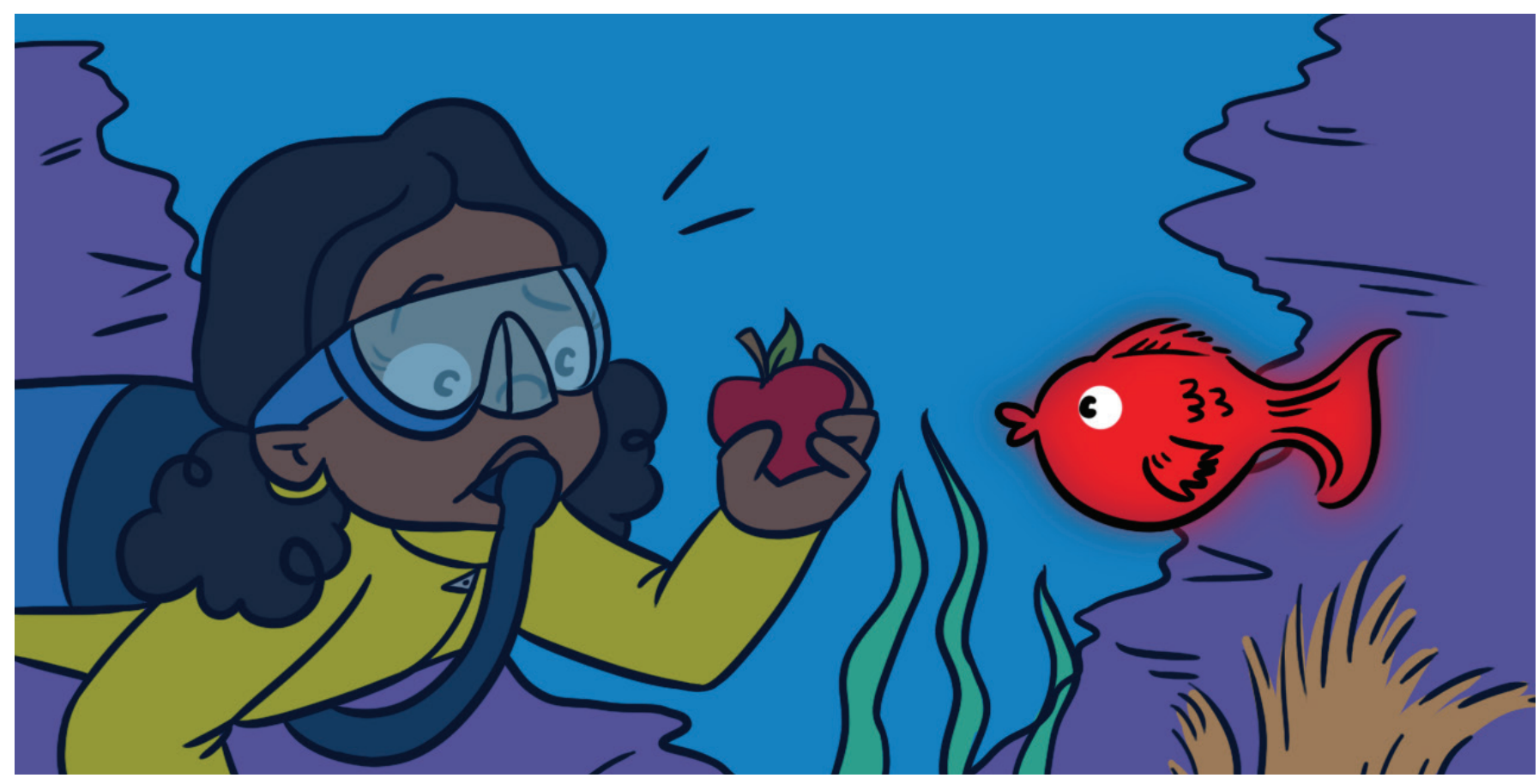

\title{
FISH GLOW FLUORESCENT RED IN THE DEEP, BLUE SEA
}

\section{Melissa Grace Meadows*}

Biology Department, Saint Francis University, Loretto, PA, United States

YOUNG REVIEWERS:

\begin{tabular}{|l|l}
\hline TEAN & MILL CREEK \\
UPTON ELEMENTARY
\end{tabular}

AGES: $10-11$
Under the sea, everything looks blue because the water absorbs all the red light but not the blue light. This means that fish cannot be very colorful down there. Some fish seem to do the impossible thougheven though all the light is blue, they are bright red! Those fish have special fluorescent colors that absorb blue light and bounce back red light instead. But why? We discovered three interesting reasons why fish are fluorescent red. Some of them use red fluorescent colors as camouflage, so they can sneak up on their food. Other fish use it as a bright red flashlight to see their food better. Some fish show off to their potential mates with fluorescent red fins. I hope that finding out about how beautiful these fish are inspires you to help protect these incredible fish and their ocean.

\section{WHY IS THE OCEAN BLUE?}

Have you ever wondered why water in a cup looks clear, but ocean water looks blue? The ocean looks blue because there is so much water. 


\section{PIGMENT}

A molecule that absorbs some colors of light and reflects others.

Figure 1

(A) Marine life looks very colorful near the surface. If you took an apple with you on a dive, it would look red (as usual). (B) When you scuba dive down to 60 feet, to you or a fish that lives there, everything looks blue, even a red apple. Background photos by Dr. Melissa Meadows taken at about 1 and 60 feet deep with no color adjustment. Apples have been superimposed on these pictures to simulate how red light is absorbed by water.
White light from the sun is actually a mixture of red, green, and blue light; you can see this every time you see a rainbow. As sunlight goes through water, the red part of the light gets absorbed by the water molecules, but the blue light does not. This absorbance of red light by water molecules is similar to the way pigment molecules in a blue shirt absorb red and green light and reflect, or bounce back, blue light so you can see it. So, when you have deep water, like in the ocean, you end up with only the blue light bouncing back out of the water to your eyes [1].

But what does it look like underwater? Well, the exact same thing happens. At the very surface of the water, like if you go snorkeling on a tropical coral reef, you can see many colors. The white light does not have to go through a lot of water at the surface, so that means the red is not fully absorbed by the shallow water. If you take a red apple snorkeling with you, it still looks red a few feet under the surface, because it can still bounce red light back to your eyes (Figure 1A).

But what happens if you are scuba diving? As you go deeper and deeper, the colors start to disappear, as they are absorbed by all of the water molecules between you and the sun. First, you do not see any red, and then orange and yellow go away, and, if you go really deep, then green disappears, too. By the time you are 60 feet under the waves, everything looks blue. Your apple now looks like a kind of grayish blue-yuck (Figure 1B)! It is still a red apple, but down here, there is no red light to bounce back to your eyes. Red fish look grayish-blue too... ...unless the fish is not just plain red, but fluorescent red!

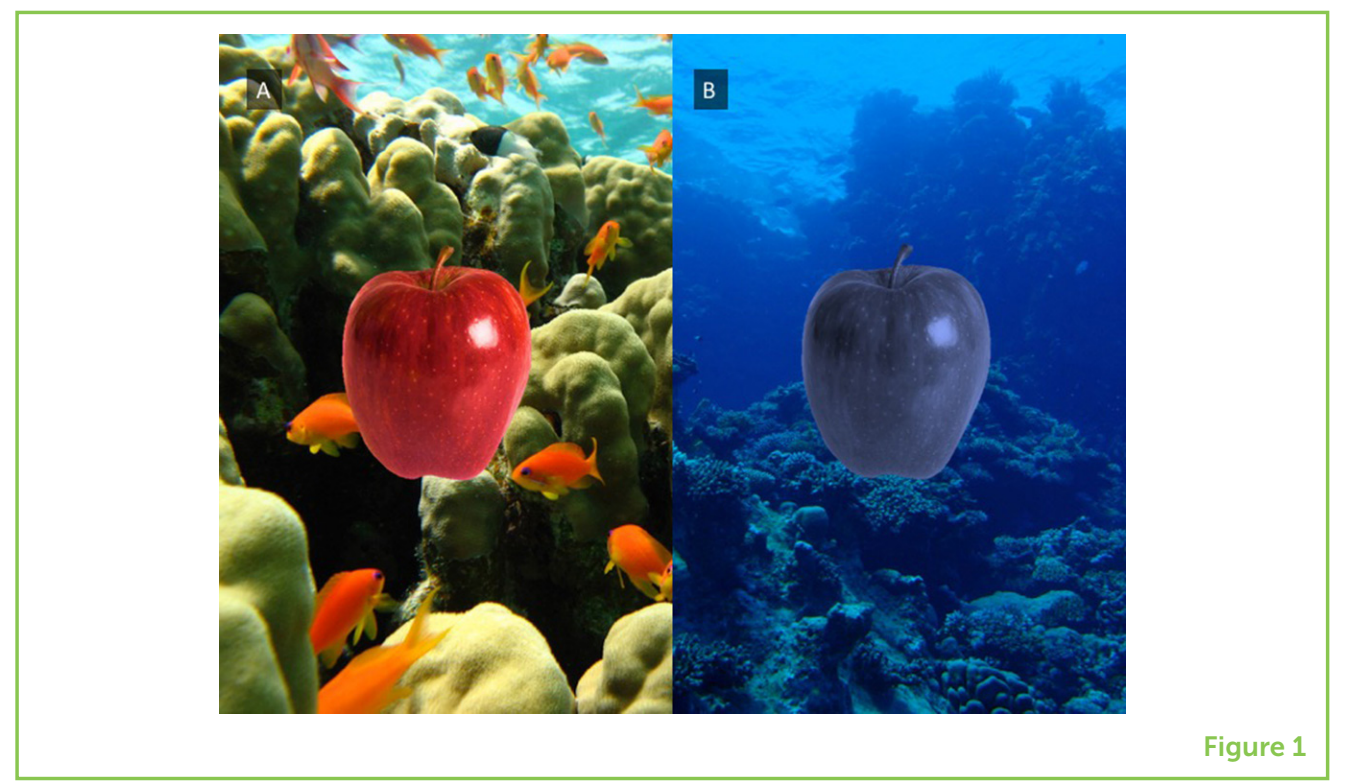




\section{FLUORESCENCE}

When a pigment absorbs one color of light and then emits a different color of light.

\section{CAMOUFLAGE}

When an object blends in with its background making it difficult to see.

\section{HOW CAN A RED FISH BE RED IN THE DEEP, BLUE SEA?}

Fluorescent fish seem almost magical. There is no red light in the deeper part of the reef and that means most normal fish can only look blue or blackish. But fluorescent red fish shine bright red against all that deep blue. Is it magic...or is it science?

You guessed it-science! Fluorescent colors are very special. You might have seen fluorescence before if you have ever seen a blacklight poster or paint illuminated with blacklight. Fluorescent colors seem to glow, because they absorb one color of light and then they emit a different color. This is because of the way the pigment (color) molecules release energy from the light they absorb. When a pigment molecule absorbs light energy, it usually slowly releases the energy as heat. Instead, a fluorescent molecule releases some of the energy from the light it absorbed as new light that has lower energy than the light that was absorbed. Normal pigments just cannot do this-they can only bounce back colors of light that exist already in their environment. That is why fluorescent colors look amazing and a bit unbelievable.

Remember how everything looks blue when you are 60 feet under the sea? Like living blacklight posters, fluorescent fish absorb that blue light, and then they emit red light. Fish that live in deeper, bluer water have even brighter red fluorescence [2]. Since 2008, hundreds of fluorescent ocean fish have been discovered by marine biologists [3, 4]. But, until now, we did not know much about why these fish are fluorescent. In a new research study, we looked at the advantages fish might have by being fluorescent red.

\section{WHY ARE FISH FLUORESCENT?}

There are a lot of reasons why animals have certain colors. We had several ideas about why certain types of fish might have red fluorescent color patterns, including these three hypotheses:

1. Hypothesis 1: Camouflage? First, fish might use red fluorescence to blend in, or camouflage, with red fluorescent backgrounds. Some kinds of seaweed that fish sit on shine fluorescent red. Like a deer hunter wearing a camouflage coat, we expected that fish that like to sit and wait for their prey (the animals that they eat) without being seen would be more likely to have a patchy, or broken up, pattern of fluorescence that looks like their seaweed background. 
2. Hypothesis 2: Red flashlight eyes? Second, fish with fluorescent eyes might be using their eyes as little red flashlights to shine on their prey. Some tiny prey animals have eyes that are very shiny. A red flashlight in a blue environment would make the prey's eyes stand out! We expected that fish that eat this tiny prey with shiny eyes would be more likely to have fluorescent eyes than other fish that eat different prey.

3. Hypothesis 3: Showing off? Third, fish might use bright fluorescent red fins to show off to their potential mates. A lot of fish parade around with colorful fins waving like flags that say "pay attention to ME!" Are shining fluorescent red fins a great way to get noticed against the blue sea background? If so, fish species in which you can easily tell the difference between female (girl) and male (boy) fish should be more likely to have fluorescent fins.

\section{HOW DID WE STUDY FLUORESCENCE IN FISH?}

To find out whether fish use fluorescence for camouflage, red flashlights, or showing off, we looked for red fluorescence in 665 different kinds of fish. Then, we took pictures of the fluorescent ones using blue light, just like if they were underneath the sea. This made it easy to see the fluorescent red and to say whether each fish had fluorescent

Figure 2

\section{(A-C) Red eye}

fluorescence could be used as red flashlights to make prey with shiny eyes easier to see.

(D, E) Fluorescent fins could be used to show off to potential mates.

(F, G) Patchy red fluorescence could be used to camouflage and hide from prey against a red fluorescent background of seaweed, corals, or sponges. Photos by Dr. Nico Michiels, published in the source article. All images here have been taken in blue light so that fluorescence can be viewed. For images of fluorescent fish under fluorescence and non-fluorescence light conditions, please see Meadows et al. [2]. eyes, patchy "camouflage" fluorescence, or fluorescent fins (Figure 2). Another person, who did not know which fish were fluorescent, looked

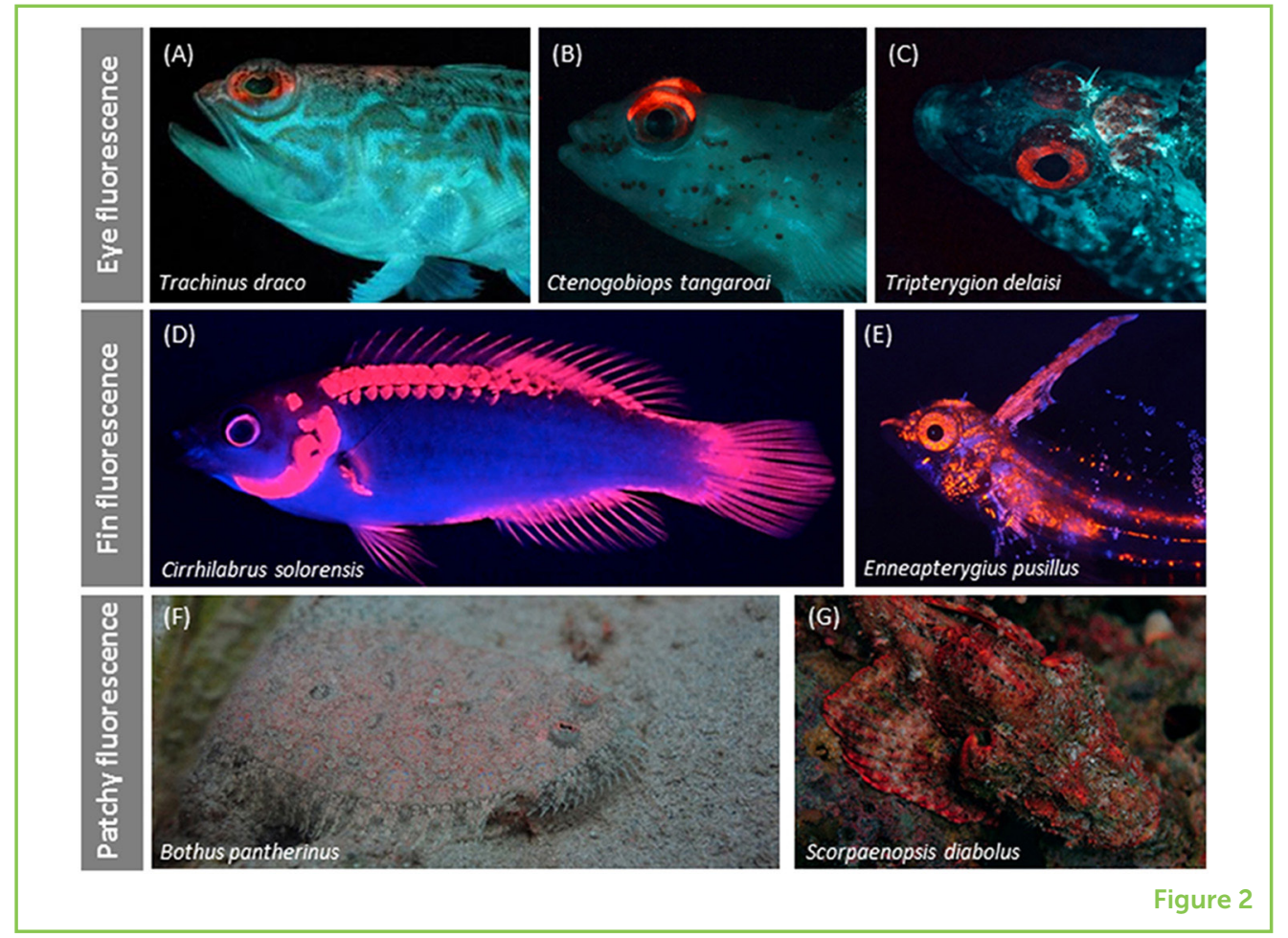


ECOLOGY

How animals interact with their environments and with each other.

\section{BIOLUMINESCENCE}

When organisms make their own light using chemical reactions. in books to find out more about the ecology of these fish. Ecology is how animals interact with their environment and with each other. We looked at whether each fish was a sit-and-wait bottom predator or a free-swimming predator, ate tiny prey with shiny eyes, or had patterns that allow people to tell the male and female fish apart.

\section{WHAT DID WE DISCOVER?}

We discovered that 272 out of the 665 fish that we studied are fluorescent red, which means there are actually a whole lot of fluorescent fish out there that scientists did not know about. This is important, because it means this is not actually a rare type of fish coloration. We discovered that many fish use fluorescence to be red in the deep part of the ocean. Without using fluorescent colors, being red would not be possible below 60 feet underwater. This is a newly discovered type of color that is important for other scientists to understand, if they want to know about how fish interact with one another and with their environment.

Hypothesis 1: Camouflage? We only saw patchy fluorescence that could be used for camouflage in a few of the types of fish that swim in the water to catch prey. In contrast, over $70 \%$ of the fish that sit and wait on the bottom of the ocean to capture unsuspecting prey have a patchy camo-pattern of fluorescence, which supports hypothesis 1 (Figure 3A). Fish with a fluorescent red camo-pattern are often seen sitting on fluorescent things such as corals, sponges, and seaweed. When sitting on a patchy red fluorescent background, these fish use their fluorescence to blend in and hide from their prey. Then they just wait until their prey comes close and gobble them up!

Hypothesis 2: Red flashlight eyes? About 75\% of fish that eat tiny prey with shiny eyes have fluorescent red eyes, which supports hypothesis 2. Less than $50 \%$ of fish that eat prey with no eyes at all have red fluorescent eyes (Figure 3B). This means that the red fluorescent eyes are probably really used as flashlights! Red fluorescent fish light up their prey's shiny eyes, so that they can see the prey's eyes shining red against a blue background.

Really cool fish called flashlight fish do pretty much the same thing, but with bioluminescence instead. Flashlight fish have pouches under their eyes that bioluminescence or make their own light using chemical reactions. This works just like the fireflies you may have caught in your backyard in the summer. Flashlight fish can light up to communicate at night. 
Figure 3

Results. (A) Percentages of fish that have patchy red fluorescent bodies and are either freeswimming predators or sit-and-wait predators. There are more sit-and-wait predators with patchy fluorescent body patterns than free-swimming predators, supporting the hypothesis that patchy fluorescence is used for camouflage.

(B) Percentages of fish with fluorescent eyes that eat prey with no eyes or tiny prey with shiny eyes. There are more fish with fluorescent eyes who eat tiny prey with shiny eyes than fish with fluorescent eyes who eat prey that do not have eyes, supporting the hypothesis that fish use fluorescence around their eyes to light up the shiny eyes of their prey. (C)

Percentage of fish with fluorescent fins that have differences between males and females and where males and females look the same. There are more fish with fluorescent fins where males and females look different than where males and females look the same, supporting the hypothesis that fin fluorescence is used to show off to mates. Figure drawn by Dr. Melissa Meadows based on data in the source article.

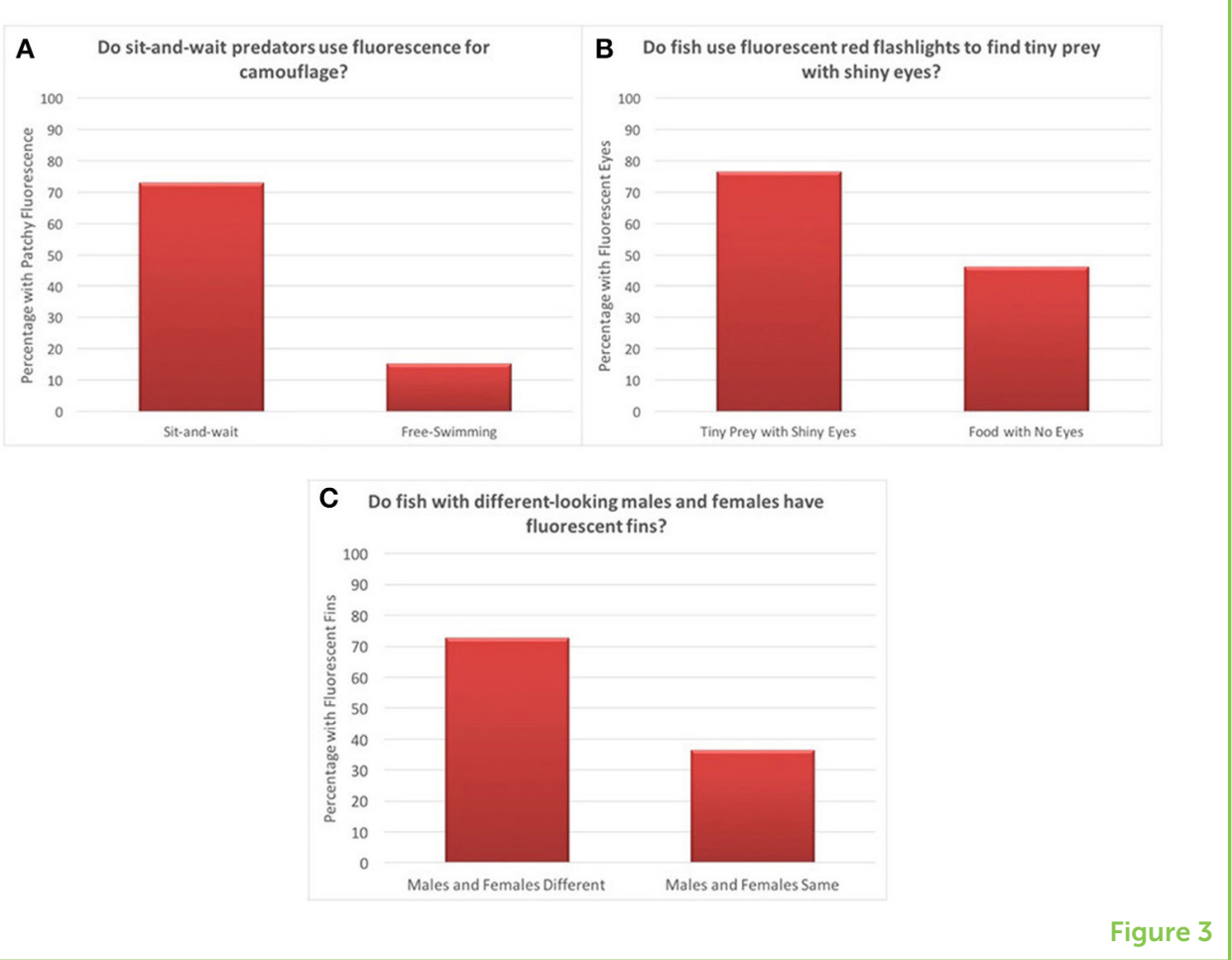

Hypothesis 3: Showing off? About $85 \%$ of fish species that have obvious differences between males and females have red fluorescent fins, which supports hypothesis 3. In fish species in which males and females look the same, $<50 \%$ have fluorescent fins (Figure $3 \mathrm{C}$ ). This means that red fluorescent fins are probably used by a lot of fish to signal whether they are males or females. These brightly colored fins would be really easy to see against the blue water below 60 feet. What a great way to show off to a potential mate! Fins can also be moved up and down, so the fish can hide their bright red flags when predators come around.

\section{WHY ARE RED FLUORESCENT FISH IMPORTANT?}

I think it is really neat that fish can have colors that, on first glance, seem impossible to create. They can be red even though all the light is blue where they live. To marine biologists like me, this is amazing. I hope that knowing a little more about how beautiful these fish are and why they have such incredible red fluorescence inspires kids, their parents, and teachers to love the ocean even more. Please join me and other marine biologists in our work to conserve this ecosystem and all of its diverse organisms. In addition, you never know what discoveries will be useful to humans eventually. Fluorescent pigments from jellyfish are currently used to visualize different parts of cells, to 
diagnose diseases, and even to make some television screens. The fluorescent pigments in fish may be important in medicine or other fields someday.

\section{ORIGINAL SOURCE ARTICLE}

Anthes, N., Theobald, J., Gerlach, T., Meadows, M. G., and Michiels, N. K. 2016. Diversity and ecological correlates of red fluorescence in marine fishes. Front. Ecol. Evol. 4:126. doi: 10.3389/fevo.2016.00126

\section{REFERENCES}

1. Jerlov, N. G. 1968. Optical Oceanography. New York, NY: Elsevier.

2. Meadows, M. G., Anthes, N., Dangelmayer, S., Alwany, M. A., Gerlach, T., Schulte, G., et al. 2014. Red fluorescence increases with depth in reef fishes, supporting a visual function, not UV protection. Proc. R. Soc. B Biol. Sci. 281:20141211. doi: 10.1098/rspb.2014.1211

3. Michiels, N. L., Anthes, N., Hart, N. S., Herler, J., Meixner, A. J., Schleifenbaum, F., et al. 2008. Red fluorescence in reef fish: a novel signaling mechanism? BMC Ecol. 8:16. doi: 10.1186/1472-6785-8-16

4. Sparks, J. S., Schelly, R. C., Smith, W. L., Davis, M. P., Tchernov, D., Pieribone, V. A., et al. 2014. The covert world of fish biofluorescence: a phylogenetically widespread and phenotypically variable phenomenon. PLOS ONE 9:e83259. doi: 10.1371/journal.pone.0083259

SUBMITTED: 22 March 2018; ACCEPTED: 08 October 2018; PUBLISHED ONLINE: 31 October 2018.

EDITED BY: Michele A. Johnson, Trinity University, United States

CITATION: Meadows MG (2018) Fish Glow Fluorescent Red in the Deep, Blue Sea. Front. Young Minds 6:59. doi: 10.3389/frym.2018.00059

CONFLICT OF INTEREST STATEMENT: The author declares that the research was conducted in the absence of any commercial or financial relationships that could be construed as a potential conflict of interest.

COPYRIGHT @ 2018 Meadows. This is an open-access article distributed under the terms of the Creative Commons Attribution License (CC BY). The use, distribution or reproduction in other forums is permitted, provided the original author(s) and the copyright owner(s) are credited and that the original publication in this journal is cited, in accordance with accepted academic practice. No use, distribution or reproduction is permitted which does not comply with these terms. 


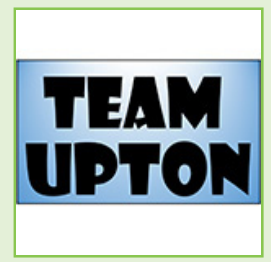

\section{YOUNG REVIEWERS}

\section{MILL CREEK ELEMENTARY, AGES: 10-11}

We are Team Upton! We are a group of 5th graders (ages 10-11) from Missouri, USA. We are a creative and active class - we especially enjoy recess, P.E., and art. Our class is talkative and good at many different things, so we worked really well as a team to review this article. We liked working with Ellee and Ronnie to learn about fluorescent fish and why the ocean is blue, and hope you do too!

\section{AUTHOR}

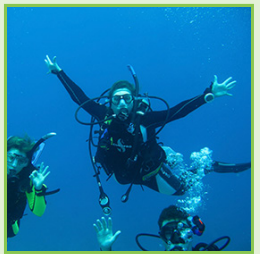

\section{MELISSA GRACE MEADOWS}

Melissa Meadows leads the Marine Biology and Aquarium and Zoo Science programs at Saint Francis University in Loretto, PA. She has worked on all kinds of topics in animal coloration and marine biology, from iridescence in hummingbirds to coral reef conservation, and of course fluorescence in fish! She has been all over the world for research and field trips, including the Florida Keys, St. Lucia, Germany, the Red Sea in Egypt, Italy, France, New Zealand, and the Galapagos Islands. She is a scuba Instructor and loves being underwater, especially introducing students to the coral reef! *mmeadows@francis.edu 